time he breathed quite freely through the opening, the sides of which I continued to hold apart. He could not bear the introduction of a tube; and fearing that, if the tabe should slip out, he might die immediately-which I have seen happen,-I removed a small circular piece, about the size of an ordinary shirt button, from the front of the trachea. He now breathed through the opening quite freely, drank a cup of beef-tea and a glass of wine, and then lay down and went off to sleep. He passed a quiet night, waking occasionally to take nourishment, and breathing quite freely, altogether through the opening. The next morning the cervical and submaxillary glands were larger, and the throat apparently completely blocked up with slough, having now an abominable fetor. The respiration was quite calm, and he was able to swallow his nourishment. At five P.M. he was much lower; and, gradually sinking, he died between nine and ten o'clock, the breathing being perfectly easy up to the last.

Now this case, although terminating fatally, clearly shows the benefit which may be hoped from the performance of tracheotomy; indeed, I am only sorry that I did not recommend it sooner. When performed, the child was fast dying a most distressing death from apnœea; unable to swallow, for every effort was directed to breathing. All this was immediately relieved by the operation; life was certainly prolonged. And I have little doubt that, had not the original disease continued to progress unfavourably, the patient would have had at least a good chance of recovery through the operation.

Queen's-road, Dalston, Aug. 1867.

\section{STONE IN THE BLADDER OF LARGE SIZE; LITHOTOMY ; RECOVERY.}

By JOHN BURNS, EsQ.,

FELLOW OF THE FACULTY OF PHYSICIANS AND SUBGEONS, GLASGOW.

THe patient, whose case is here described, did not by any means appear a favourable subject for operation, so far as prognosis goes. Nevertheless, the result has been complete recovery.

J. C-, aged thirty-six, formerly a schoolmaster, now a pawnbroker, consulted me in the month of June last year. He had been suffering great internal pain, particularly in voiding urine, for a very long period; and, having heard that I had operated on a man in his immediate neighbourhood a few days before for stone, he expressed fears that something of that kind was wrong with him, and had been so nearly all his life, but that he could never muster courage to submit to an examination, and now his life had become so miserable that he had resolved to have something done. I advised him to allow me to pass a sound at once; and he submitted. I passed the sound, and had no difficulty in striking a stone, which seemed to be of large size-indeed, the patient heard the clink of the staff on the stone the moment I struck it; yet he expressed doubts as to submitting to an operation, and at this $I$ was not astonished. His general health seemed greatly broken down; chest much contracted; shoulders raised; cough tickling and incessant; and for nearly thirty years he had not slept on a dry bed in consequence of his urine trickling away whenever he assumed the recumbent position. His penis was shrivelled, with tenderness to touch, and scalding pain in voiding urine.

I expressed my own doubts to himself and his friends as to the result of an operation, but as he had become so utterly helpless and his life miserable, I advised him to submit. He went away with a view to make up his mind, and I saw no more of him till about the end of January of the present year, when he returned to say that he had resolved to undergo the operation, and he wished me to proceed with it at once.

On the 1st of February last $I$ accordingly proceeded with the operation. I was assisted by Dr. Hunter, of Glasgow, and Mr. William M'Gregor Burns, of Ayr.

While we were in process of administering chloroform, and while the patient was inhaling it, his jaws suddenly became locked, and we were obliged to desist until they were prised apart and respiration resumed. I thereupon performed the lateral operation, making the incision of the ordinary size; but no sooner did my finger touch the stone than $I$ found it to be of no ordinary dimensions. I enlarged the wound a little more before introducing the large forceps, but on passing them I found it impossible to grasp the stone until I had enlarged the opening into the bladder still more. When $I$ caught the stone in the forceps, so enormous did it seem to be that $I$ again let it go, thinking I had caught it by its longest diameter; but on turning it round as I best could, I was unable to lay hold of a narrower grasp, and, with all the traction I could exercise, I was unable to move the stone until I had caught the forceps in my left hand and cut its way out, in doing which I accidentally wounded the rectum. Yet during all this difficult and complicated operation there was not half an ounce of blood lost. After the patient was at first completely under the influence of chloroform, he did not require it to be further administered during the operation. He recovered consciousness in a few minutes after his removal to bed, and from then till now he has never had an unfavourable symptom. No catheter was ever passed, but the urethra, as well as the wound, was washed out frequently with tepid water, and a few drops of Condy's fluid by means of a syringe. The wound is now entirely closed, and the patient has been at business for nearly four weeks, and now enjoys better health than he has experienced for many years.

I weighed the stone on the day of the operation, and its weight was then upwards of six ounces and three-quarters. Its greatest circumference measured nine inches; its circumference by its short diameter, seven inches and a half. Its measurement now is eight inches and three-quarters by seven inches and a half. I may state that the patient is married, and the. father of three children.

Glasgow, Aug. 1867.

$\mathrm{ON}$

$$
\text { G O U T Y B R O N C H I T I S. }
$$

By GEO. GREGORY, EsQ., L.R.C.P. LOND.

For about three years my attention has been awakened to the connexion which sometimes exists between rheumatism, or gouty rheumatism, and bronchitis. I was therefore pleased to read in ' 1 'HE LANCET recently the excellent lecture by Dr. E. Headlam Greenhow on Gouty Bronchitis, as well as the annotation in the same number on this subject.

I have placed Dr. Greenhow's heading, "On Gouty Bronchitis," at the beginning of these remarks more out of courtesy to him than as a fit index to these observations; for whilst I am persuaded that I have met with several cases of rheumatic bronchitis, some of which were of a rheumatic gouty character, I have not seen bronchitis caused or associated with goutprobably because I see few cases of gout.

I have met with two cases (adult men), both of whom have been again and again afflicted with rheumatic gout associated or alternating with bronchitis, during the last two or three years, there having been attacks about every three months. The symptoms were those common to rheumatic gout and to a recent attack of bronchitis in one who had previously suffered from bronchitis. In both patients there was now and then considerable hæmorrhage from the hæmorrhoidal vessels. They were both wine-drinkers, and both were sometimes exposed to dampness from rain and badly-drained houses, with flagged floors.

About fourteen years ago I read the late Dr. Paris's Pharmacologia. In it I remember he alluded to the unfitness of certain vegetable bitters, especially fermented bitters, in bronchitis; and Dr. Chambers, in his valuable Clinical Lectures, considers that vegetable bitters are injurious in rheumatism.

I have frequently proved the accuracy of both of these views. Do not these statements form a circle of facts, which in part explain the origin of rheumatic gout and bronchitis, as well as confirm the opinion of Dr. Greenhow, that there is such a disease as bronchitis caused by the blood-poison of rheumatic gout?

Bolton, August, 1867.

British Medical Assoctation. - The following preparations were exhibited by Mr. Lockhart Clarke at the recent annual meeting held in Dublin :-1. Atrophy of the nerve-cells and various lesions of the spinal cord in muscular atrophy. 2. Atrophy of the nerve-cells of the olivary bodies in hemiplegia with loss of speech. 3. Abnormal bloodvessels and nerve-cells of the cerebral convolutions in general paralysis of the insane. 4. Characteristic lesions of the spinal cord in locomotor ataxy. 5. Lesions of the spinal cord in tetanus. 6. Lesions of the brain, medulla oblongata, and spinal cord in different kinds of paralysis. 